\title{
Investigating vomiting and/or bloody diarrhoea in Campylobacter jejuni infection
}

\begin{abstract}
Correspondence
lain A. Gillespie

lain.Gillespie@hpa.org.uk
\end{abstract}

Received 18 November 2005

Accepted 30 January 2006 lain A. Gillespie, ${ }^{1}$ Sarah J. O'Brien, ${ }^{2}$ Jennifer A. Frost, ${ }^{3}$ Clarence Tam, ${ }^{1}$ David Tompkins, ${ }^{4}$ Keith R. Neal, ${ }^{5}$ Qutub Syed, ${ }^{6}$ Michael J. G. Farthing, ${ }^{7}$ and The Campylobacter Sentinel Surveillance Scheme Collaboratorst

\author{
${ }^{1}$ Environmental and Enteric Diseases Department, Health Protection Agency (HPA) Centre for \\ Infections, 61 Colindale Avenue, London NW9 5EQ, UK \\ ${ }^{2}$ Division of Medicine and Neuroscience, Manchester University, Clinical Sciences Building, \\ Hope Hospital, Stott Lane, Salford M6 8HD, UK \\ ${ }^{3}$ Welsh Assembly, Cardiff CF99 1NA, UK \\ ${ }^{4} \mathrm{HPA}$ Yorkshire and the Humber Regional Microbiology, Bridle Path, York Road, Leeds \\ LS15 7TR, UK \\ ${ }^{5}$ Division of Epidemiology and Public Health, School of Community Health Sciences, University \\ of Nottingham Medical School, Nottingham NG7 2UH, UK \\ 6HPA North West, Rooms 103-112, First Floor, DBH House, 105 Boundary Street, Liverpool \\ L5 9YJ, UK \\ ${ }^{7}$ St George's Hospital Medical School, University of London, Cranmer Terrace, London \\ SW17 ORE, UK
}

Campylobacter jejuni infection frequently presents as acute enteritis with diarrhoea, malaise, fever and abdominal pain. Vomiting and bloody diarrhoea are reported less frequently. To investigate potential host, micro-organism or environmental factors that might explain the different clinical presentations, the features of laboratory-confirmed Campylobacter jejuni cases presenting with vomiting and/or bloody diarrhoea were compared with cases who did not report either clinical manifestation. Single variable analysis and logistic regression were employed. Explanatory variables included food, water and environmental risks. Cases who reported vomiting and/or bloody diarrhoea tended to suffer a longer illness and were more likely to require hospital admission. Independent risks identified were being a child, female gender, consumption of poultry other than chicken, pre-packed sandwiches and sausages, and reported engineering work or problems with drinking-water supply. A dose-response relationship with vomiting and/or bloody diarrhoea and increasing daily consumption of unboiled tap water was observed also. Vomiting and/or bloody diarrhoea characterized the more severe end of the disease spectrum and might relate to host susceptibility and/or infective dose. The role of unboiled tap water as a potential source of C. jejuni infection in England and Wales requires further investigation.
Abbreviations: $\mathrm{Cl}$, confidence interval; HPA, Health Protection Agency; OR, odds ratio.

†The Campylobacter Sentinel Surveillance Scheme Collaborators are public health, environmental health and laboratory staff who serve the populations of the following health authorities: Birmingham, Bradford, Bro Taf, Bury and Rochdale, Dyfed Powys, East Kent, Barnet, Enfield and Haringey, Herefordshire, Leeds, Leicestershire, Manchester, North Cumbria, North Essex, North West Lancashire, Nottingham, Salford and Trafford, South and West Devon, South Lancashire, Southampton and South West Hampshire, Stockport, West Pennine, Wigan and Bolton. In association with: HPA Laboratory of Enteric Pathogens, Campylobacter Reference Unit; HPA Centre for Infections, Environmental and Enteric Diseases Department; HPA Local and Regional Services; HPA Statistics Unit.

\section{INTRODUCTION}

Campylobacter infection represents a significant and persistent public health problem in the UK. Approximately 40000 laboratory-confirmed cases are reported annually in England and Wales (Health Protection Agency, 2005), a figure which is estimated to underascertain disease in the community by a factor of eight (Wheeler et al., 1999). The disease is unpleasant and debilitating, with approximately $10 \%$ of cases requiring hospital treatment as a result of their infection (Gillespie et al., 2002). Sequelae that can accompany illness, such as reactive arthritis, toxic megacolon and Guillain-Barré syndrome, add to the disease burden (Hahn, 1998). 
Infection with Campylobacter jejuni most frequently presents as acute enteritis. Classic medical textbook descriptions of Campylobacter enteritis list the commonly reported symptoms as diarrhoea, malaise, fever and abdominal pain (Blaser, 2000; Skirrow, 1996). The spectrum of diarrhoea ranges from loose stools through profuse watery diarrhoea to frankly bloody stools (Blaser, 2000). Tissue injury can occur along the bowel from jejunum to colon, and gross pathological examination of the gut in severe cases reveals a diffuse, bloody, oedematous and exudative enteritis (Blaser, 2000; King, 1962). Severe disease may be clinically, sigmoidoscopically and histologically difficult to differentiate from ulcerative colitis, and Campylobacter infection forms part of the differential diagnosis for inflammatory bowel disease (Lambert et al., 1979). Abdominal pain may be so severe that Campylobacter enteritis can be confused with acute appendicitis (Blaser et al., 1979; Lambert et al., 1979).

In the first year of a population-based sentinel surveillance study of Campylobacter infection in England and Wales, diarrhoea (95\%), abdominal pain (85\%) and fever $(78 \%)$ were the most commonly reported symptoms, whilst vomiting $(35 \%)$ and bloody diarrhoea $(27 \%)$ were reported less frequently (Communicable Disease Surveillance Centre, 2001). To investigate potential host, micro-organism or environmental factors that might explain the different clinical presentations, we compared the features of $C$. jejuni cases presenting with vomiting and/or bloody diarrhoea with cases who did not report either clinical manifestation.

\section{METHODS}

The Campylobacter Sentinel Surveillance Scheme has been described in detail elsewhere (Gillespie et al., 2002). In brief, standardized clinical and epidemiological data, generated through postal questionnaires, were integrated with microbiological typing data for laboratoryconfirmed cases of Campylobacter infection in participating health authorities in England and Wales. The scheme began on 1 May 2000 (Communicable Disease Surveillance Centre, 2000b) and ran until 30 April 2003. The response rate was consistently over $75 \%$ (The Campylobacter Sentinel Surveillance Scheme Collaborators, 2003).

Statistical analysis, performed using Stata statistical software release 8.0 (StataCorp, College Station, TX), was restricted to cases of C. jejuni infection who had not travelled abroad in the 2 weeks before illness to control for the confounding effect of foreign travel. Cases who were infected with more than one Campylobacter subtype [as defined by serotyping (Frost et al., 1998), phage-typing (Frost et al., 1999) and/or antimicrobial resistance pattern (Thwaites \& Frost, 1999)] were excluded, as were cases whose specimen dates were either prior to, or greater than 31 days from, their onset date.

The date of illness onset was used to define the season in which illness commenced. Season was coded to compare cases with an onset in spring (March to May) with those who were ill in summer (June to August), autumn (September to November) and winter (December to February). Patients' description of their ethnic origin was classified according to the UK census 2001 (Office for National Statistics, 2001). Age values were recoded to compare infants ( $<1$ year of age) with toddlers (1-4 years), young children (5-9 years), older children and teenagers (10-17 years), adults (18-64 years) and the elderly $(\geqslant 65$ years). Food exposures were coded to compare cases who had eaten a food once or more than once in the exposure period (2 weeks prior to the onset of symptoms) with those who had not. Contact with raw meat was coded to compare no contact with once, two to five times, six to ten times and more than eleven times. Daily consumption of unboiled tap water was recoded to compare zero consumption with one to four, five to nine and $\geqslant 10$ glasses drunk. Binary variables were created to compare the 10 most commonly identified serotypes of $C$. jejuni with other known serotypes. Individuals with missing information for any of the variables of interest were omitted from the analyses using those variables.

For the case-case comparison, cases of $C$. jejuni infection reporting vomiting and/or bloody diarrhoea were considered 'cases', whilst those who did not report either symptom were considered 'controls'. It is important to note that symptoms were self-reported. The demographic and clinical profiles of cases and controls were compared using Pearson's chi square test and Student's $t$ test. Differences in exposure were compared initially using simple logistic regression models. Point estimates and $95 \%$ confidence intervals (CIs) for the Mantel-Haenszel odds ratio (OR) were calculated for each explanatory variable whilst controlling for the effect of age.

Proximal (Victora et al., 1997) exposures with a $P$ value of less than $0 \cdot 1$ were then included in a larger model to obtain maximum-likelihood estimates of the effect of exposures on the outcome of interest, whilst controlling for confounding. The distal (Victora et al., 1997) exposures age, gender, season and ethnicity were included and retained in the model throughout. The significance of exposures was tested using the likelihood ratio (LR) test, and the model was simplified accordingly.

\section{RESULTS AND DISCUSSION}

Linked epidemiological and microbiological data were available for 11831 cases of $C$. jejuni infection referred during the study (1 May 2000 to 30 April 2003). Cases ranged from less than 1 month to 97 years of age (median 39 years), and the gender distribution was even. Nine hundred and seven of 11693 cases $(8 \%)$ were admitted to hospital as a result of their illness.

Amongst those cases who reported their foreign travel status (11 648; $98 \%$ ), 2261 cases (19\%) had travelled abroad in the 2 weeks before illness. Cases who reported foreign travel or who did not report their foreign travel status were excluded, as were cases $(51 ; 0 \cdot 44 \%)$ infected with more than one subtype, and 397 cases (3\%) for whom the recorded specimen date preceded the reported onset date $(n=69)$ or exceeded it by $>31$ days $(n=328)$. This left 9350 UKacquired cases of $C$. jejuni infection for analysis.

Diarrhoea, abdominal pain and fever were reported by 9056 $(96 \cdot 9 \%), 8114(86 \cdot 8 \%)$ and $7440(79 \cdot 6 \%)$ cases, respectively. Vomiting was reported by 3346 cases $(35 \cdot 8 \%)$ and bloody diarrhoea by 2661 cases $(28.5 \%)$, and cases who reported one of these symptoms were more likely to report the other $\left(\chi^{2} 138 \cdot 19 ; P<0 \cdot 001\right)$. In total, 4043 cases $(43 \cdot 2 \%)$ reported one or both clinical presentations. These cases were compared with the 3335 cases $(35 \cdot 7 \%)$ who reported no vomiting or bloody diarrhoea. A further 1972 cases $(21 \cdot 1 \%)$ who did not respond to the questions of vomiting and/or bloody diarrhoea were excluded from further analysis. Cases who reported vomiting and/or bloody diarrhoea experienced 
a longer illness than cases who did not report either symptom (mean 11.8 versus 10.9 days; $t$ test $P=0.007$ ) and were more likely to be admitted to hospital ( $11 \cdot 8 \%$ versus $5 \cdot 1 \%$; $\chi^{2}$ 99.5; $\left.P<0 \cdot 001\right)$.

\section{Single variable analysis}

Self-reported vomiting and/or bloody diarrhoea amongst cases of $C$. jejuni infection decreased with age (Table 1). Cases who reported vomiting and/or bloody diarrhoea were more likely to be female and were more likely to report the consumption of barbecued foods, pre-packed sandwiches, sausages, and foods eaten in restaurants. They were more likely to have reported a number of water exposures and to have been exposed to pet cats. They were less likely to report the consumption of fish and shellfish, cheese and salad. Reported vomiting and/or bloody diarrhoea appeared to differ depending on infecting serotype.

\section{Logistic regression analysis}

Independent risks for being a case of C. jejuni infection who reported vomiting and/or bloody diarrhoea were being an infant and being of female gender, and the consumption of

Table 1. Risk exposures for reported vomiting and/or bloody diarrhoea in C. jejuni infection

Single variable logistic regression analysis (variables with a $P$ value of $<0 \cdot 1$ shown).

\begin{tabular}{|c|c|c|c|c|c|c|}
\hline \multirow[t]{2}{*}{ Exposure } & \multicolumn{2}{|c|}{ Percentage exposed } & \multirow[t]{2}{*}{ OR } & \multicolumn{2}{|c|}{$95 \% \mathrm{CI}$} & \multirow[t]{2}{*}{$P$ value } \\
\hline & Cases $^{\star}(n=4043)$ & Controls $\dagger(n=3335)$ & & Lower & Upper & \\
\hline Female gender & $51 \cdot 6$ & $47 \cdot 7$ & $1 \cdot 24$ & $1 \cdot 13$ & $1 \cdot 36$ & $<0 \cdot 001$ \\
\hline Infants & $3 \cdot 9$ & $1 \cdot 2$ & $1 \cdot 0$ & - & - & - \\
\hline $1-4$ years & $9 \cdot 3$ & $5 \cdot 2$ & $0 \cdot 56$ & $0 \cdot 38$ & $0 \cdot 82$ & $0 \cdot 003$ \\
\hline $5-9$ years & $3 \cdot 5$ & $2 \cdot 2$ & $0 \cdot 49$ & $0 \cdot 31$ & $0 \cdot 77$ & $0 \cdot 002$ \\
\hline $10-17$ years & $5 \cdot 0$ & $3 \cdot 4$ & $0 \cdot 45$ & $0 \cdot 30$ & $0 \cdot 69$ & $<0 \cdot 001$ \\
\hline $18-64$ years & $69 \cdot 1$ & $67 \cdot 8$ & $0 \cdot 32$ & $0 \cdot 22$ & $0 \cdot 45$ & $<0 \cdot 001$ \\
\hline$\geqslant 65$ years & $9 \cdot 3$ & $20 \cdot 2$ & $0 \cdot 14$ & $0 \cdot 10$ & $0 \cdot 21$ & $<0 \cdot 001$ \\
\hline Foods eaten in restaurants & $51 \cdot 7$ & $47 \cdot 9$ & $1 \cdot 18$ & $1 \cdot 07$ & $1 \cdot 31$ & $<0.001$ \\
\hline Barbecued foods & $17 \cdot 4$ & $14 \cdot 8$ & $1 \cdot 16$ & $1 \cdot 02$ & $1 \cdot 34$ & $0 \cdot 03$ \\
\hline Pre-packed sandwiches & $44 \cdot 7$ & $41 \cdot 9$ & $1 \cdot 16$ & $1 \cdot 04$ & $1 \cdot 28$ & $0 \cdot 01$ \\
\hline Poultry other than chicken & $19 \cdot 6$ & $18 \cdot 1$ & $1 \cdot 14$ & $1 \cdot 00$ & $1 \cdot 29$ & $0 \cdot 05$ \\
\hline Sausages & $60 \cdot 9$ & $59 \cdot 2$ & $1 \cdot 12$ & $1 \cdot 01$ & $1 \cdot 23$ & $0 \cdot 03$ \\
\hline Salad & $71 \cdot 1$ & $76 \cdot 4$ & $0 \cdot 87$ & $0 \cdot 77$ & $0 \cdot 98$ & $0 \cdot 02$ \\
\hline Cheese & $77 \cdot 7$ & $82 \cdot 3$ & $0 \cdot 86$ & $0 \cdot 76$ & $0 \cdot 98$ & $0 \cdot 02$ \\
\hline Fish and shellfish & $55 \cdot 8$ & $63 \cdot 6$ & $0 \cdot 82$ & $0 \cdot 74$ & $0 \cdot 91$ & $<0 \cdot 001$ \\
\hline Unpasteurized milk & $8 \cdot 0$ & $6 \cdot 7$ & $1 \cdot 21$ & $1 \cdot 00$ & $1 \cdot 45$ & $0 \cdot 05$ \\
\hline Engineering work/supply problems $\ddagger$ & $7 \cdot 3$ & $5 \cdot 0$ & $1 \cdot 52$ & $1 \cdot 24$ & $1 \cdot 86$ & $<0 \cdot 001$ \\
\hline Water from private supplies & $7 \cdot 2$ & $5 \cdot 1$ & $1 \cdot 43$ & $1 \cdot 14$ & $1 \cdot 78$ & $<0 \cdot 001$ \\
\hline Bottled water & $51 \cdot 8$ & $45 \cdot 9$ & $1 \cdot 28$ & $1 \cdot 15$ & $1 \cdot 42$ & $<0 \cdot 001$ \\
\hline Glasses of water $§$ drunk daily: none & $10 \cdot 5$ & $12 \cdot 6$ & 1 & - & - & - \\
\hline One to four & $64 \cdot 0$ & $68 \cdot 0$ & $1 \cdot 18$ & $1 \cdot 00$ & $1 \cdot 39$ & $0 \cdot 05$ \\
\hline Five to nine & $22 \cdot 5$ & $17 \cdot 7$ & $1 \cdot 51$ & $1 \cdot 25$ & $1 \cdot 83$ & $<0 \cdot 001$ \\
\hline$\geqslant 10$ & $3 \cdot 0$ & $1 \cdot 7$ & $2 \cdot 07$ & $1 \cdot 42$ & $3 \cdot 01$ & $<0.001$ \\
\hline Windsurfing & $0 \cdot 37$ & $0 \cdot 13$ & $2 \cdot 80$ & $0 \cdot 91$ & $8 \cdot 57$ & $0 \cdot 07$ \\
\hline Fishing & $1 \cdot 64$ & $1 \cdot 01$ & $1 \cdot 60$ & $1 \cdot 04$ & $2 \cdot 47$ & $0 \cdot 03$ \\
\hline Contact with a pet hamster & $4 \cdot 7$ & $3 \cdot 1$ & $1 \cdot 41$ & $0 \cdot 97$ & $2 \cdot 04$ & $0 \cdot 07$ \\
\hline Contact with a pet cat & $48 \cdot 2$ & $43 \cdot 4$ & $1 \cdot 20$ & $1 \cdot 05$ & $1 \cdot 38$ & $0 \cdot 01$ \\
\hline HS50 versus other serotypes & $21 \cdot 6$ & $17 \cdot 8$ & $1 \cdot 25$ & $1 \cdot 08$ & $1 \cdot 44$ & $<0.001$ \\
\hline HS2 versus other serotypes & $5 \cdot 2$ & $4 \cdot 3$ & $1 \cdot 16$ & $0 \cdot 89$ & $1 \cdot 51$ & $0 \cdot 27$ \\
\hline HS13 versus other serotypes & $24 \cdot 5$ & $22 \cdot 0$ & $1 \cdot 16$ & $1 \cdot 02$ & $1 \cdot 33$ & $0 \cdot 03$ \\
\hline HS31 versus other serotypes & $7 \cdot 6$ & $8 \cdot 5$ & $0 \cdot 97$ & $0 \cdot 79$ & $1 \cdot 19$ & $0 \cdot 75$ \\
\hline HS37 versus other serotypes & $4 \cdot 3$ & $5 \cdot 6$ & $0 \cdot 71$ & $0 \cdot 55$ & $0 \cdot 92$ & $0 \cdot 01$ \\
\hline HS18 versus other serotypes & $3 \cdot 5$ & $5 \cdot 1$ & 0.69 & $0 \cdot 52$ & $0 \cdot 91$ & $0 \cdot 01$ \\
\hline
\end{tabular}

${ }^{*}$ Cases of C. jejuni infection who reported vomiting and/or bloody diarrhoea.

$\dagger$ Cases of C. jejuni infection who did not report vomiting and/or bloody diarrhoea.

$\ddagger$ In relation to mains water.

§Unboiled tap water. 
poultry other than chicken, pre-packed sandwiches and sausages (Table 2). The likelihood of reported vomiting and/or bloody diarrhoea increased with reported engineering work or problems with drinking water supply and with increasing daily consumption of unboiled tap water. Cases infected with serotype HS37 were less likely to report bloody diarrhoea than those cases infected with other serotypes.

We have analysed data from a large sentinel surveillance scheme for Campylobacter infection in England and Wales in order to identify clinical, epidemiological or microbiological features leading to reported vomiting and/or bloody diarrhoea amongst UK-acquired cases of $C$. jejuni infection. A number of points need to be considered when interpreting these findings.

Firstly, cases included in this study were those whose infections were confirmed using microbiological methods. These cases are likely to represent the more severe end of the clinical spectrum (Tam et al., 2003). Secondly, exposure data were self-reported over a 2-week period prior to onset, increasing the likelihood of reporting bias. There is no reason to believe, however, that these biases operate differently in those who were included as 'cases' in the analysis compared

Table 2. Independent risk exposures for reported vomiting and/or bloody diarrhoea in C. jejuni infection

Final logistic regression model including age, gender, season and ethnicity (non-significant distal measurements not shown).

\begin{tabular}{|c|c|c|c|c|}
\hline \multirow[t]{2}{*}{ Exposure } & \multirow[t]{2}{*}{ OR } & \multicolumn{2}{|c|}{$95 \% \mathrm{CI}$} & \multirow{2}{*}{$\begin{array}{c}P \\
\text { value }\end{array}$} \\
\hline & & Lower & Upper & \\
\hline Female gender & $1 \cdot 25$ & $1 \cdot 07$ & $1 \cdot 46$ & $0 \cdot 01$ \\
\hline Infants & $1 \cdot 0$ & - & - & - \\
\hline $1-4$ years & $0 \cdot 37$ & $0 \cdot 12$ & $1 \cdot 13$ & $0 \cdot 08$ \\
\hline 5-9 years & $0 \cdot 23$ & $0 \cdot 07$ & $0 \cdot 74$ & $0 \cdot 01$ \\
\hline $10-17$ years & $0 \cdot 20$ & $0 \cdot 06$ & $0 \cdot 63$ & $0 \cdot 01$ \\
\hline $18-64$ years & $0 \cdot 17$ & $0 \cdot 06$ & $0 \cdot 50$ & $<0 \cdot 001$ \\
\hline$\geqslant 65$ years & $0 \cdot 10$ & $0 \cdot 03$ & $0 \cdot 29$ & $<0 \cdot 001$ \\
\hline Poultry other than chicken & $1 \cdot 26$ & $1 \cdot 03$ & $1 \cdot 54$ & $0 \cdot 02$ \\
\hline Pre-packed sandwiches & $1 \cdot 20$ & $1 \cdot 02$ & $1 \cdot 41$ & $0 \cdot 03$ \\
\hline Sausages & $1 \cdot 18$ & $1 \cdot 00$ & $1 \cdot 39$ & $0 \cdot 05$ \\
\hline Salad & $0 \cdot 79$ & $0 \cdot 65$ & $0 \cdot 96$ & $0 \cdot 02$ \\
\hline Cheese & $0 \cdot 81$ & $0 \cdot 66$ & $0 \cdot 99$ & $0 \cdot 04$ \\
\hline Fish and shellfish & $0 \cdot 79$ & $0 \cdot 67$ & $0 \cdot 93$ & $<0 \cdot 001$ \\
\hline $\begin{array}{l}\text { Engineering work/supply } \\
\text { problems }\end{array}$ & $1 \cdot 52$ & $1 \cdot 10$ & $2 \cdot 11$ & $0 \cdot 01$ \\
\hline \multicolumn{5}{|l|}{ Glasses of water $\dagger$ drunk daily: } \\
\hline none & 1 & - & - & - \\
\hline One to four & $1 \cdot 29$ & $1 \cdot 00$ & $1 \cdot 67$ & $0 \cdot 05$ \\
\hline Five to nine & $1 \cdot 79$ & $1 \cdot 33$ & $2 \cdot 40$ & $<0 \cdot 001$ \\
\hline$\geqslant 10$ & $2 \cdot 02$ & $1 \cdot 10$ & $3 \cdot 70$ & $0 \cdot 02$ \\
\hline HS37 versus other serotypes & $0 \cdot 66$ & $0 \cdot 46$ & $0 \cdot 94$ & $0 \cdot 02$ \\
\hline
\end{tabular}

${ }^{\star}$ In relation to mains water.

$\dagger$ Unboiled tap water. with 'controls'. Thirdly, it has been suggested that coinfections might provide an explanation for the observed vomiting and/or bloody diarrhoea. Data on co-infections were unavailable and a degree of uncontrolled confounding might therefore have occurred. However, in general, low levels of co-infection for campylobacters are reported in the literature (Blaser et al., 1983; The Food Standards Agency, 2000), so this is unlikely to have had a major effect on the findings. Finally, it is possible that additional confounding factors not included in our analysis affected our results. However, we have captured standardized information on a wide range of exposures for a large number of cases of $C$. jejuni infection, so the likelihood of this taking place has been minimized.

We elected to consider symptoms of vomiting and bloody diarrhoea together. Our a priori hypothesis was that vomiting and bloody diarrhoea did not share a common aetiology. However, the fact that cases who reported one of the symptoms were more likely to report the other suggested that this was not the case. Furthermore, initial analyses (not shown) examining each symptom separately produced very similar findings, reinforcing the need for a combined analysis.

Reported vomiting and/or bloody diarrhoea was strongly related to the age of the case. This might relate to host susceptibility or might represent ascertainment bias. It is possible that the relatively immature colonic flora (Stark \& Lee, 1982) and intestinal immune system (Davies, 1988) of the infant might lead to a more severe infection and hence clinical presentation (Blaser, 2000). Alternatively, these are alarming symptoms that parents might be more likely to report on behalf of their children. The observed inverse 'dose-response' relationship with increasing age group, however, suggests perhaps that the effect is a genuine one.

The direction of the association amongst the food variables independently associated with vomiting and/or bloody diarrhoea warrants comment. Whether or not these findings represent different levels of contamination with $C$. jejuni is uncertain, but since it is possible that some foods are more highly contaminated than others, this might help to explain these observations (i.e. it is not the food items per se, but rather the contamination levels that are important).

The direction of association with the water-exposure variables and in particular the dose-response relationship between drinking unboiled tap water and presenting with vomiting and/or bloody diarrhoea were intriguing. Casecase comparisons, as used in this study, should not be used to make statements about the magnitude or direction of population risk (McCarthy \& Giesecke, 1999; Gillespie et al., 2002). Nevertheless, finding a dose-response relationship adds weight to an association between an exposure and disease (Hill, 1965), suggesting that there might be a real effect on clinical presentation. We cannot be absolutely certain, however, whether increased consumption of unboiled tap water was a cause of infection (and hence symptoms) or a consequence of it. 
Outbreaks of Campylobacter infection linked with municipal water supplies have been reported in the past (Communicable Disease Surveillance Centre, 2000a; Melby et al., 1991; Mentzing, 1981; Palmer et al., 1983; Vogt et al., 1982). In all of these studies, either the water supply was unchlorinated (Melby et al., 1991; Mentzing, 1981) or a serious challenge to a chlorinated supply occurred prior to the outbreak (Communicable Disease Surveillance Centre, 2000a; Palmer et al., 1983; Vogt et al., 1982). Case-control studies of sporadic infection have failed to identify municipal mains water as a source of infection (Adak et al., 1995; Eberhart-Phillips et al., 1997; Kapperud et al., 1992; Neal \& Slack, 1997; Rodrigues et al., 2001). This might represent a negligible/ zero risk, or might relate to the high prevalence of exposure to drinking mains water amongst the general population in many countries, making an effect difficult to detect.

Under current UK regulations, drinking water supplied for domestic purposes or to food production premises should be regarded as wholesome if it does not contain any microorganisms or parasites at a concentration or value that would constitute a potential danger to human health (Department of the Environment, Transport and the Regions, 2000). Indicator organisms (historically coliforms and Escherichia coli, but current legislation includes enterococci) are used to ensure this quality and to assess the effectiveness of water treatment (especially disinfection). However, indicator organisms such as E. coli might not be an adequate indicator for the presence of campylobacters in water (Environment Agency, 2002), and statutory testing for campylobacters is not undertaken.

There was only one (inverse) association between infecting serotype and presentation with vomiting and/or bloody diarrhoea in this study. This suggests, perhaps, that there is no fundamental relationship between pathogenicity and expression of surface antigens detected by phenotyping (Frost et al., 1998). Further work on the genetic basis of pathogenesis could be undertaken by the molecular subtyping of the isolates referred in this study.

\section{Conclusions}

Vomiting and/or bloody diarrhoea characterized the more severe end of the disease spectrum, as evidenced by a longer illness and increased hospital admissions. Host susceptibility might be important, as witnessed by strongly agerelated symptom presentation. Infective dose might also be a factor. The role of unboiled tap water as a potential source of $C$. jejuni infection in England and Wales requires further investigation.

\section{ACKNOWLEDGEMENTS}

This work was presented in part in a poster at CHRO 2003, Twelfth International Workshop on Campylobacter, Helicobacter and Related Organisms, 6-10 September 2003, Aarhus, Denmark. Thanks are extended to Dr Sally Millership for comments on this manuscript.
Membership of the Campylobacter Sentinel Surveillance Scheme Steering Committee:

Mr A. Charlett (Head, Statistics, Modelling and Bioinformatics, HPA Centre for Infections); Dr J. M. Cowden (Consultant Epidemiologist, Health Protection Scotland); Mrs J. A. Frost (Welsh Assembly, Cardiff); Mr I. A. Gillespie (Clinical Scientist, Environmental and Enteric Diseases Department, HPA Centre for Infections); Ms J. Millward (Principal Environmental Health Officer, Birmingham City Council); Dr K. R. Neal, (Clinical Reader in the Epidemiology of Communicable Diseases, Division of Epidemiology and Public Health, University of Nottingham); Professor S. J. O'Brien (Division of Medicine and Neuroscience, Manchester University); Dr M. J. Painter (Consultant in Communicable Disease Control, Manchester Health Authority); Professor Q. Syed (Regional Director, HPA North West); Dr D. Tompkins (Regional Microbiologist, HPA Yorkshire and the Humber).

\section{REFERENCES}

Adak, G. K., Cowden, J. M., Nicholas, S. \& Evans, H. S. (1995). The Public Health Laboratory Service national case-control study of primary indigenous sporadic cases of campylobacter infection. Epidemiol Infect 115, 15-22.

Blaser, M. J. (2000). Campylobacter jejuni and related species. In Mandell, Douglas and Bennett's Principles and Practice of Infectious Diseases, 5th edn, vol. 2, pp. 2276-2285. Edited by G. L. Mandell, J. E. Bennett \& R. Dolin. Philadelphia: Churchill Livingstone.

Blaser, M. J., Berkowitz, I. D., LaForce, F. M., Cravens, J., Reller, L. B. \& Wang, W. L. (1979). Campylobacter enteritis: clinical and epidemiologic features. Ann Intern Med 91, 179-185.

Blaser, M. J., Wells, J. G., Feldman, R. A., Pollard, R. A. \& Allen, J. R. (1983). Campylobacter enteritis in the United States. A multicenter study. Ann Intern Med 98, 360-365.

Communicable Disease Surveillance Centre (2000a). Outbreak of campylobacter infection in a south Wales valley. CDR Wkly 10, 427-430.

Communicable Disease Surveillance Centre (2000b). Sentinel surveillance of campylobacter in England and Wales. CDR Wkly 10, 169-172.

Communicable Disease Surveillance Centre (2001). Campylobacter Sentinel Surveillance Scheme. CDR Wkly 11, (23) 7 June 2001. Available online at http://www.hpa.org.uk/cdr/archives/2001/cdr2301.pdf

Davies, E. G. (1988). Immunodeficiency. In Textbook of Pediatrics, 5th edn, pp. 1231-1272. Edited by A. G. M. Campbell \& N. McIntosh. London: Churchill Livingstone.

Department of the Environment Transport and the Regions (2000). The Water Supply (Water Quality) Regulations 2000. Statutory Instrument No. 3184.

Eberhart-Phillips, J., Walker, N., Garrett, N., Bell, D., Sinclair, D., Rainger, W. \& Bates, M. (1997). Campylobacteriosis in New Zealand: results of a case-control study. J Epidemiol Community Health 51, 686-691.

Environment Agency (2002). The Microbiology of Drinking Water (2002) - Part 1 - Water Quality and Public Health. http://www. environment-agency.gov.uk/commondata/acrobat/mdwpart1.pdf

Frost, J. A., Oza, A. N., Thwaites, R. T. \& Rowe, B. (1998). Serotyping scheme for Campylobacter jejuni and Campylobacter coli based on direct agglutination of heat-stable antigens. J Clin Microbiol 36, 335-339.

Frost, J. A., Kramer, J. M. \& Gillanders, S. A. (1999). Phage typing of Campylobacter jejuni and Campylobacter coli and its use as an adjunct to serotyping. Epidemiol Infect 123, 47-55. 
Gillespie, I. A., O’Brien, S. J., Frost, J. A., Adak, G. K., Horby, P., Swan, A. V., Painter, M. J. \& Neal, K. R. (2002). A case-case comparison of Campylobacter coli and Campylobacter jejuni infection: a tool for generating hypotheses. Emerg Infect Dis 8, 937-942.

Hahn, A. F. (1998). Guillain-Barré syndrome. Lancet 352, 635-641. Health Protection Agency (2005). Campylobacter spp. Laboratory reports of faecal isolates. England and Wales, 1986-2004. http:// www.hpa.org.uk/infections/topics_az/campy/data_ew.htm.

Hill, A. B. (1965). The environment and disease: association or causation? Proc R Soc Med 58, 295-300.

Kapperud, G., Skjerve, E., Bean, N. H., Ostroff, S. M. \& Lassen, J. (1992). Risk factors for sporadic Campylobacter infections: results of a case-control study in southeastern Norway. J Clin Microbiol 30, 3117-3121.

King, E. O. (1962). The laboratory recognition of Vibrio fetus and a closely related vibrio isolated from human cases of vibriosis. Ann N Y Acad Sci 90, 700.

Lambert, M. E., Schofield, P. F., Ironside, A. G. \& Mandal, B. K. (1979). Campylobacter colitis. Br Med J 1, 857-859.

McCarthy, N. \& Giesecke, J. (1999). Case-case comparisons to study causation of common infectious diseases. Int J Epidemiol 28, 764-768.

Melby, K., Gondrosen, B., Gregusson, S., Ribe, H. \& Dahl, O. P. (1991). Waterborne campylobacteriosis in northern Norway. Int J Food Microbiol 12, 151-156.

Mentzing, L. O. (1981). Waterborne outbreaks of campylobacter enteritis in central Sweden. Lancet 2, 352-354.

Neal, K. R. \& Slack, R. C. (1997). Diabetes mellitus, anti-secretory drugs and other risk factors for campylobacter gastro-enteritis in adults: a case-control study. Epidemiol Infect 119, 307-311.

Office for National Statistics (2001). Census 2001. England household form. http://www.statistics.gov.uk/census2001/pdfs/H1.pdf.

Palmer, S. R., Gully, P. R., White, J. M., Pearson, A. D., Suckling, W. G., Jones, D. M., Rawes, J. C. \& Penner, J. L. (1983). Water-borne outbreak of campylobacter gastroenteritis. Lancet 1, 287-290.
Rodrigues, L. C., Cowden, J. M., Wheeler, J. G. \& 7 other authors (2001). The study of infectious intestinal disease in England: risk factors for cases of infectious intestinal disease with Campylobacter jejuni infection. Epidemiol Infect 127, 185-193.

Skirrow, M. B. (1996). Enteropathogenic bacteria: Enterobacteria and miscellaneous enteropathogenic and food-poisoning bacteria. In Oxford Textbook of Medicine, 3rd edn, vol. 1, pp. 550-560. Edited by D. J. Weatherall, J. G. G. Ledingham \& D. A. Warrell. Oxford: Oxford University Press.

Stark, P. L. \& Lee, A. (1982). The microbial ecology of the large bowel of breast-fed and formula-fed infants during the first year of life. J Med Microbiol 15, 189-203.

Tam, C. C., Rodrigues, L. C. \& O'Brien, S. J. (2003). The study of infectious intestinal disease in England: what risk factors for presentation to general practice tell us about potential for selection bias in case-control studies of reported cases of diarrhoea. Int J Epidemiol 1, 99-105.

The Campylobacter Sentinel Surveillance Scheme Collaborators (2003). Ethnicity and Campylobacter infection: a population-based questionnaire survey. J Infect 47, 210-216.

The Food Standards Agency (2000). Microbiological findings. In A Report of the Study of Infectious Intestinal Disease in England, pp. 85-112. London: The Stationery Office.

Thwaites, R. T. \& Frost, J. A. (1999). Drug resistance in Campylobacter jejuni, C. coli and C. lari isolated from humans in north west England and Wales, 1997. J Clin Pathol 52, 812-814.

Victora, C. G., Huttly, S. R., Fuchs, S. C. \& Olinto, M. T. (1997). The role of conceptual frameworks in epidemiological analysis: a hierarchical approach. Int J Epidemiol 26, 224-227.

Vogt, R. L., Sours, H. E., Barrett, T., Feldman, R. A., Dickinson, R. J. \& Witherell, L. (1982). Campylobacter enteritis associated with contaminated water. Ann Intern Med 96, 292-296.

Wheeler, J. G., Sethi, D., Cowden, J. M., Wall, P. G., Rodrigues, L. C., Tompkins, D. S., Hudson, M. J. \& Roderick, P. J. (1999). Study of infectious intestinal disease in England: rates in the community, presenting to general practice and reported to national surveillance. $B M J 318,1046-1050$. 